\title{
RELACIONES ENTRE LA REPRESENTACIÓN ANTROPOMORFA-ZOOMORFA DE PIEZAS PREHISPÁNICAS DE LA REGIÓN CENTRAL DE COSTA RICA Y DOS CARTAS DE JUAN VÁZQUEZ DE CORONADO DEL SIGLO XVI
}

\author{
Henry O. Vargas Benavides
}

\begin{abstract}
RESUMEN
El siguiente trabajo analiza dos cartas del conquistador y pacificador español Juan Vázquez de Coronado del año 1563 a través de dos aspectos principales: el primero, un mapa tomado del libro Garcimuñoz. La ciudad que nunca murió, de Carlos Molina Montes de Oca (1993) y una comparación con la plataforma virtual de Google Maps; se considera el recorrido perpetrado por el conquistador, junto a su tropa de españoles y otra de indígenas que parten desde Garcimuñoz a Quepos y hasta la región de los Coctos. El segundo, cuatro figuras antropomorfas talladas en piedra de la región central de Costa Rica y una pieza de oro de la subregión Diquís, todas de la colección del Museo Nacional de Costa Rica; estas a su vez se contrastan con características de poblados como el de Quepos (cacicazgo de Corrohore) y el de los guerreros coctos descritos en ambas cartas. Palabras clave: Cartas de Juan Vázquez de Coronado, mapa sobre la conquista, arqueología, diseño precolombino, semiótica.
\end{abstract}

\begin{abstract}
The following study analyzes two letters written in 1563 by the Spanish conqueror and peace-maker Juan Vasquez de Coronado in light of two general aspects: the first, a map taken from the book Garcimuñoz la ciudad que nunca murió by Carlos Molina Montes de Oca (1993) and a comparison with the Google Maps virtual platform. Here, the route followed by the conqueror with his troop of Spaniards and indigenous people from Garcimuñoz to Quepos and to the region of Coctos is examined. The second aspect is a series of four anthropomorphic figures carved in stone and a gold piece from the subregion of Diquis. All of them belong to the collection of the National Museum of Costa Rica. These figures contrast with the characteristics of those from settlements such as Quepos (the chieftainship of Corrohore) and the settlement of the Coctos Warriors described in both letters. Key words: Letters of Juan Vasquez de Coronado, map of conquest, archeology, pre-Columbian design, semiotics.
\end{abstract}

Dr. Henry O. Vargas Benavides. Profesor de Diseño Gráfico, Universidad de Costa Rica, Sede de Occidente. Correo electrónico: henry.vargas@ucr.ac.cr

Recepción: 04- 03- 2013

Aceptación: 19- 04- 2013 


\section{Introducción}

El juego de la mirada conllevó a la creación de "observatorios" desde un modelo militar. Así lo distingue Michel Foucault (1993) al razonar sobre la construcción de una óptica general o totalizante desde el modelo disciplinario y de poder que consiste en "encauzar" o "reeducar" conductas de los individuos. Sobre este modelo en que priva el control y la visión plantea que:

El ejercicio de la disciplina supone un dispositivo que coacciona por el juego de la mirada; un aparato en que las técnicas que permiten ver inducen efectos de poder y donde, de rechazo, los medios de coerción hacen claramente visibles aquellos sobre quienes se aplican. (1993: 175)

Nuestro observatorio parte de tres ejes: el primero, dos cartas escritas por el adelantado y conquistador español Juan Vázquez de Coronado, la primera se titula "Juan Vázquez de Coronado. Al muy ilustre señor Licenciado Juan Martínez de Landecho, presidente de la Audiencia de los Confines. De Garcimuñoz, 4 de mayo de 1563" y la segunda "Juan Vázquez de Coronado, a S.M. el Rey D. Felipe II. Del Castillo de Garcimuñoz, 2 de julio de 1563”. En ambas, describe el mismo hecho, desde su partida del centro de operaciones conocido como Garcimuñoz (en el Valle Central del territorio costarricense), hacia la costa del Pacífico, hasta llegar a dos objetivos, los cacicazgos de Quepos y luego el de los Coctos. Este último pueblo conocido por su gran agresividad y constante guerra en el que obtienen por trofeo la cabeza de sus enemigos.

El segundo, una ilustración de un mapa diseñado en 1989 y que se encuentra publicado en el libro Garcimuñoz. La ciudad que nunca murió, de Carlos Molina Montes de Oca (1993). Representa las exploraciones de los primeros conquistadores en el territorio costarricense, la de Juan de Estrada Ravago y Añez a través de la costa atlántica hacia 1560 y la de Juan Vázquez de Coronado desde el actual Valle Central de Costa Rica y a la costa pacífica hacia 1563.

El tercero, una serie de figuras de piedra prehispánica que muestra a guerreros con marcas en su cuerpo y otros cortadores de cabezas, además de un disco de oro con cuatro cabezas de la colección del Museo Nacional de Costa Rica; las tallas pertenecen a lo que se conoce como la Región Central del territorio nacional y el disco de oro a la subregión Diquís.

El fin primordial tiene un carácter comparativo en donde se miran las similitudes y diferencias entre las dos cartas de Juan Vázquez de Coronado de 1563, la ilustración de un mapa trazado en setiembre de 1989 del libro de Carlos Molina de Montes de Oca; las piezas arqueológicas de la Región Central que rondan entre el periodo de 1000 al 1550 d.C. y la pieza de oro datada entre el 700 al 1550 d.C.

Con respecto al mapa, se realizó un cotejo con la plataforma virtual Google Maps, lo que permite crear una perspectiva panóptica entre la interpretación de una ilustración geográfica de 1560 a 1564 y la visión satelital contemporánea, para así comprobar los datos de recorrido en las cartas de Vázquez de Coronado.

Las piezas arqueológicas antropomorfas evidencian huellas de individuos con características guerreras, en cuanto poseen instrumentos militares, señales o marcas y cabezas trofeo que portan como máximas preseas. He aquí la comparación entre las descripciones que Juan Vázquez encuentra en el territorio de los Coctos y la evidencia arqueológica.

De momento intervenimos el mapa ilustrado que representa el inicio de la conquista del territorio de Costa Rica en donde se resalta el recorrido del español Juan Vázquez y la triada que nos compete: el Castillo de Garcimuñoz, en el Valle Central, como punto de partida y centro de operaciones, Quepos, en el Pacífico, como segundo momento y Cocto como finalización de la experiencia compartida en las dos cartas del conquistador. 


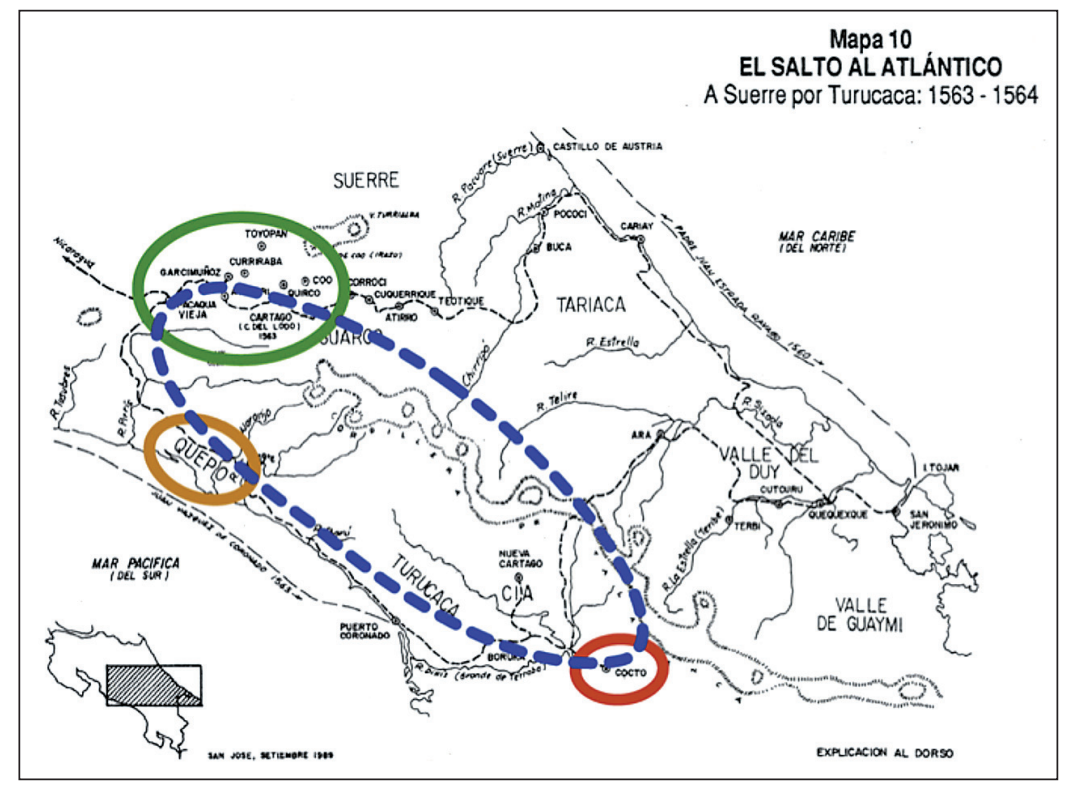

Figura 1. Mapa ilustrativo en donde se resaltan a los poblados de Garcimuñoz, Quepo y Cocto, correspondiente al siglo XVI (Molina 1993: 203)(Intervención propia)

\section{Sobre la conquista de Costa Rica}

Hacia 1542 se promulgaron las Leyes Nuevas para la protección de los indios y el establecimiento administrativo de la Audiencia de los Confines o Real Audiencia de Guatemala. Durante las primeras décadas del siglo XVI los españoles se ocuparon de explotar los recursos como el oro y esclavos en Nicaragua y Honduras y cacao en Soconusco, Guatemala y El Salvador. Sin embargo,

Costa Rica fue la última provincia conquistada en Centroamérica y, en algunos sentidos, la menos satisfactoria y la más frustrante para los españoles y criollos. También fue la más trágica para la población indígena, que luchó a intervalos, durante más de medio siglo, antes de ser dominada y casi destruida, al grado de ya no poder recuperarse posteriormente. (Kramer, Lovell y Lutz 1993: 40)

De acuerdo con Wendy Kramer, W. George Lovell y Christopher H. Lutz (1993), el territorio de Costa Rica se conquistó hasta medio siglo después del resto de las provincias de la Audiencia de los Confines, pues existían dificultades para su ocupación, sobre todo en la vertiente atlántica y una falta de interés por parte de las autoridades españolas.

No obstante, existía miedo de que la Audiencia de Panamá se extendiera hacia tierras costarricenses. Por tal motivo, se nombra Juan de Cavallón en 1560 como gobernador de Nicaragua y alcalde mayor de Nicoya y se le concede derechos para conquistar Costa Rica. La ocupación se llevó a cabo por dos sectores: la costa atlántica por parte de Estrada Ravago, tarea en la que no fructifica, y la otra desde Nicoya hacia el pacífico con un alcance limitado. $\mathrm{Al}$ entrar al oeste del Valle Central, los españoles fundan el primer asentamiento el "Castillo de Garcimuñoz", lugar que sirvió como punto de partida para las siguientes expediciones. Cavallón sufrió varias revueltas por parte de los indígenas hasta que fue sustituido por Estrada Ravago. En resumen, los autores concuerdan que la conquista costarricense se basó en el encuentro y explotación de yacimientos auríferos y una gran resistencia indígena.

Existe discrepancias entre los historiadores sobre la ubicación exacta de este primer poblado español en tierras costarricenses. Sin embargo, hay un mapa en el libro de Carlos Molina 
Montes de Oca titulado "Garcimuñoz. La ciudad que nunca murió" (1993) en el que sitúa ese lugar entre los poblados de Curriraba y Accerri, lugar que hoy se conoce como Desamparados, si lo comparamos con un mapa contemporáneo.

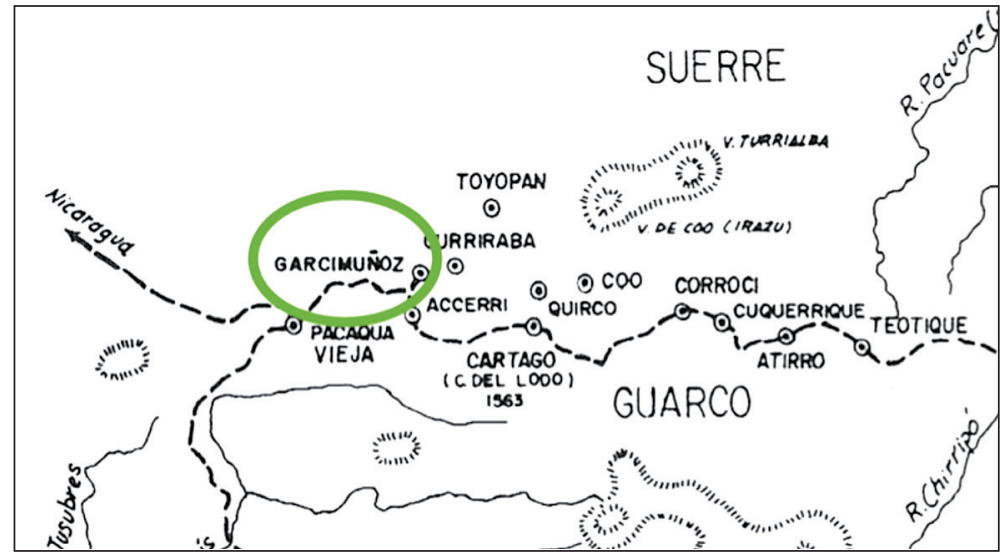

Figura 2. Detalle del mapa ilustrativo en donde se sitúa al poblado de Garcimuñoz, correspondiente al siglo XVI (Molina 1993: 203) (Intervención propia)

A través de la plataforma virtual Google Maps se compara el mapa anterior con las ciudades de Aserrí, Curridabat y Cartago. En el mapa podemos comprobar que la ciudad de Desamparados se sitúa en medio de Aserrí y Curridabat, muy cercana a la actual capital de Costa Rica, San José.

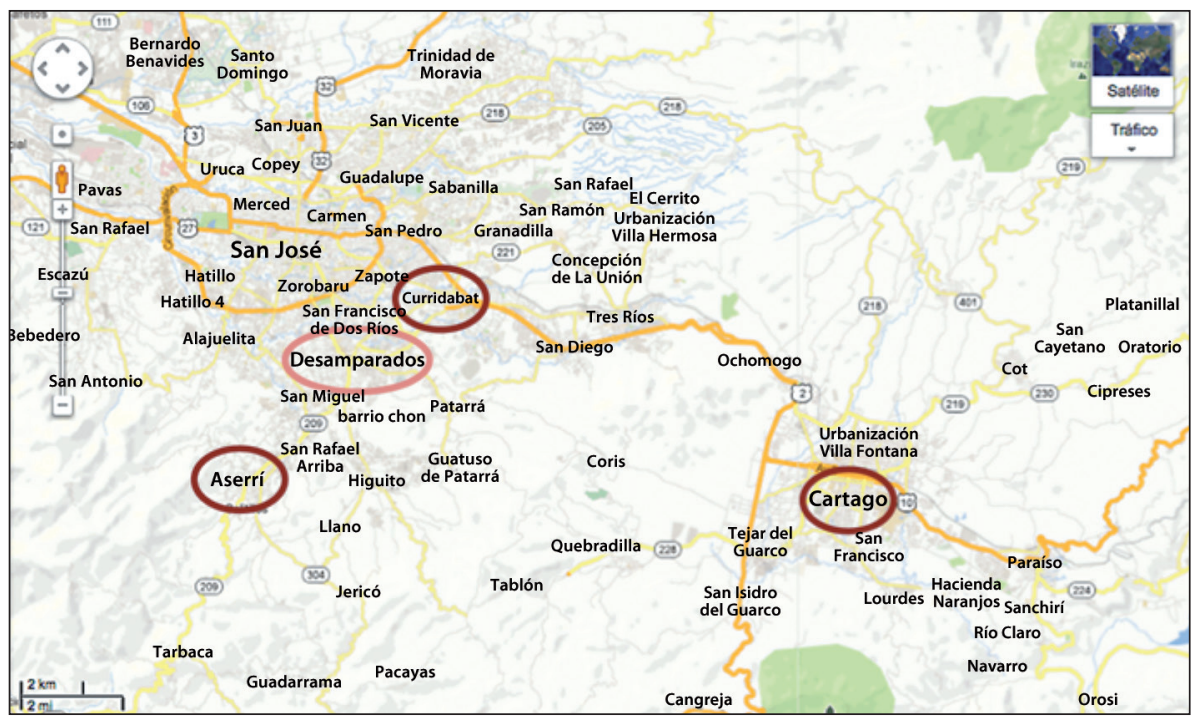

Figura 3. Detalle de las actuales ciudades de Aserrí, Curridabat y Cartago vistas por Google Maps (Intervención propia)

\section{El papel de Juan Vázquez de Coronado en la conquista del territorio costarricense}

A sus escasos diecisiete años llega a América Juan Vázquez de Coronado (15231565); permaneció primero en México y luego pasó a Guatemala. Fue partícipe en las 
conquistas de Guatemala y El Salvador. Recibió puestos de alcalde en Santiago de Guatemala, hacia 1548; luego pasó a ser también el Alcalde Mayor en San Salvador, Honduras y Nicaragua. Para abril de 1562, se le nombra en la Alcaldía Mayor de Nueva Cartago, cargo que asumió hasta finales del año.

En la provincia costarricense Juan Vázquez de Coronado reforzó la militancia, logró que le visitaran varios caciques a Garcimuñoz y les ofreció alimentación y regalos; seña de su particular trato conciliador que le caracterizó a lo largo de su misión. A principios de 1563, ya había pacificado varias provincias y tenía la intención de encontrar minas de oro en la costa caribeña. En sus expediciones por la región sur, se encontraron varios indios con diversas piezas de oro. Hacia 1563 trasladó Garcimuñoz a un mejor sitio y le denominó Cartago, conocida como Ciudad del Lodo. Encontró y repartió varios yacimientos de oro hacia la vertiente atlántica por le Valle del Duy. En octubre de 1565, Vázquez de Coronado perdió la vida en una tormenta en altamar al salir de Sanlúcar de Barrameda.

En el siguiente mapa, se observa el traslado del poblado de Garcimuñoz a Cartago, traslado que efectuó Vázquez de Coronado en el año 1563. Hacia la parte norte de esa ciudad se observa el poblado de Quirco o Quircot, y que corresponde a los territorios actuales, tanto del poblado como de la antigua capital y actual cabecera de provincia.

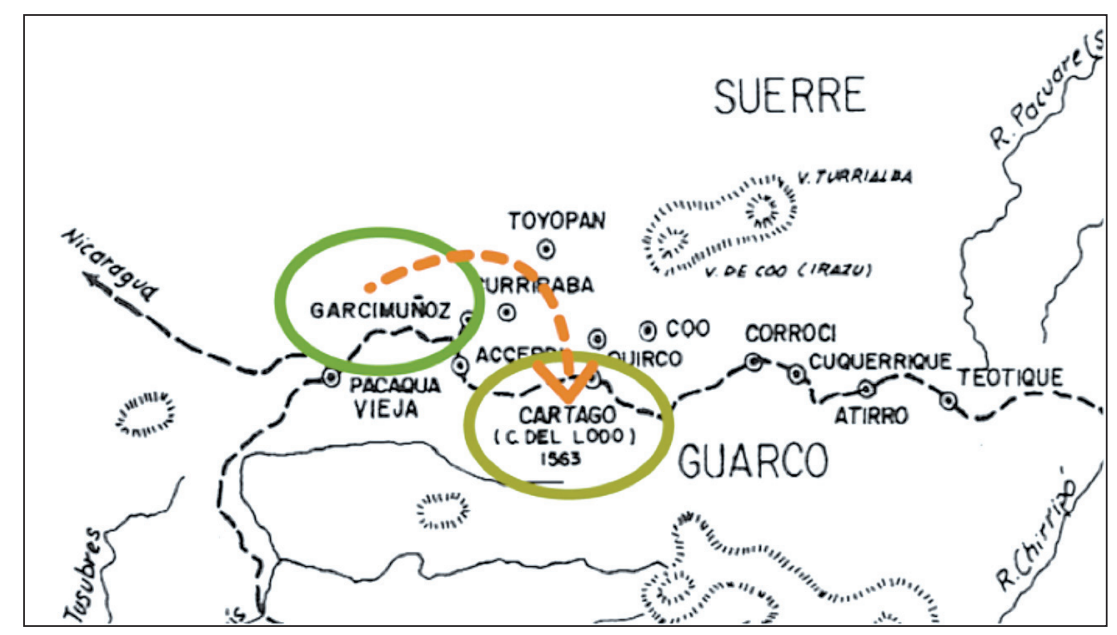

Figura 4. Detalle del mapa ilustrativo en donde se sitúa al poblado de Garcimuñoz y el de Cartago,

Ciudad del Lodo, correspondiente al siglo XVI (Molina 1993: 203) (Intervención propia)

\section{Las dos cartas de Juan Vázquez de Coronado y la relación diacrónica con las tallas prehispánicas}

La primera carta que se expone tiene fecha del 4 de mayo de 1563 y fue escrita desde el poblado de Garcimuñoz y dirigida al presidente de la Audiencia de los Confines, el muy ilustre licenciado Juan Martinez de Landecho. La segunda carta que se analiza fue escrita el 2 de julio de 1563 desde el Castillo de Garcimuñoz y dirigida a Su Majestad el Rey Felipe II.

En la primera carta, se destaca la tierra descubierta en la provincia de Costa Rica y su calidad con las palabras "una de las mejores que se an visto en la Yndias", además de exaltar sus "riquezas" y "grandezas". Recordemos que Vázquez de Coronado ya había estado por gran parte del territorio mexicano y por Centroamérica, al respecto escribe: 
Dexo descubierta a su magestad una de las mejores tierras que se an visto en las Yndias, y es poco lo que se a dicho hasta agora de las riquezas y grandezas della sin vella, en comparacion de lo que emos visto y tenemos por noticia cierta. (Fernández 1976: 94)

En el contenido del texto cita que los caciques de Abra y Acerri le piden su favor para que les ayude a resolver conflictos con sus enemigos: los caciques de los poblados de Quepos y Turucaca. Luego de pacificar, en el mes de enero, los poblados de Garavito, Coyoche, Botos, Catapas, Tices, las del Abra, Acçari, Guarco y Pacaca, emprende misión hacia Quepo en la costa pacífica con ayuda del cacique de Curiraba, su hermano Yurusti, además de los caciques Aqueçari y Pacuaca y junto con unos setenta soldados.

Para destinar el viaje, Juan Vázquez y sus ejércitos tuvieron que dirigirse de Garcimuñoz a Aserrí por los territorios actuales de Tarbaca y San Ignacio de Acosta, hasta avanzar paralelos a la costa del Pacífico y pasar cerca de Parrita hasta arribar al actual territorio del cantón de Aguirre, cuya cabecera es Quepos. Todo esto lo pudo realizar gracias a sus aliados indígenas del Valle Central, quienes conocían y utilizaban estas rutas. En ambas cartas, se confirma el paso por estas vías como puede mirarse, de igual modo, en la figura 1 (ilustración del mapa). El río Pirrís, que aparece bordeando parte de la ruta, divide los cantones actuales de Acosta y Parrita.

A su camino, Vázquez de Coronado pacificó al cacique de Tuarco y sus indígenas; a él le encontró en una gran borrachera, muchas mantas a su alrededor, al igual que piezas de oro. Antes de la llegada a Quepo envió a Ygnacio Cota como representante con más de cuarenta soldados para que la población rindiese obediencia a su majestad y se dejase predicar el evangelio. El mensajero del cacique de Corohore les recibió con: "puercos, mayz y pinol y fruta, y otro dia vino el propio cacique y truxo consigo cincuenta o sesenta indios, todos cargados de comida" (Fernández 1976: 95). Corohore les entregó como obsequio diez piezas de oro de águilas. Es de destacar la variedad de alimentos (carne, semillas y frutas) que entregaron los indígenas de Corohore a Juan Vázquez y el amplio cortejo con el que se presentó ante el adelantado español.

En la segunda carta continúa con la narración e indica que al día siguiente se presentó el cacique con setenta indígenas, cargados con bastimento, carne de danta y chanchos de monte. "[...] llamase este cacique Corrohore; es el mas lindo yndio que he visto en Yndias" (1976: 105). La referencia a la belleza de Corrohore muestra un atributo distintivo no solo en la persona del cacique, sino también en la sorpresa y fascinación del conquistador por la abundancia de aquellas tierras, en cuanto a sus alimentos y la buena dieta de estos indígenas de Quepos, la cantidad de oro que poseen, la habilidad para negociar y su amplia inteligencia para entablar distintos temas "abilisima en su manera", de buen modo "bien agestada" y de gran capacidad para pelar "belicosa, muy guerrera". Al referirse que "trata verdad" plantea la idea de personas con una alta capacidad de transparencia y resolución directa al enfrentar conflictos y que los distingue al expresar que "no se emborrachan". Aparte de las semillas y frutas, resalta también el algodón, lo que hace pensar en sus mantas, telas y distintas prendas que portaban. De igual forma, distingue el territorio con un clima y un territorio agradable para establecerse.

\footnotetext{
[...] es gente bien agestada, belicosa, muy guerrera, abilisima en su manera. Trata verdad, cosa pocas veces vista entre ellos; no se emborrachan; tienen mucho oro y ropa, grande abundancia de mantenimientos, mayz, frisoles, calabaças, algodón, yuca, platanos, çapotes y todos otros generos de frutas de las que hay en estas partes. Tiene buen temple, cielo y suelo, invierno y verano. (Fernández 1976: 105)
}

En este encuentro, Corrohore le entregó también cinco piezas de oro y otras cinco al tercer día con el fin de que le ayudase contra los indígenas de Coctu, que dista unas 25 leguas y que tenían cautivos a su hermana y otros indígenas. 
El 19 de febrero parte de Quepo a un pueblo llamado Coctu. Corohore les ofreció unos cien indios para ayudarles. Tardaron tres días en llegar por la costa pacífica, sea por la playa o cruzando montañas. Una vez instalados en Quepo o Quepos, Vázquez de Coronado emprende la misión hacia Cocto vía la costa pacífica, como puede observarse en el trazo del mapa.

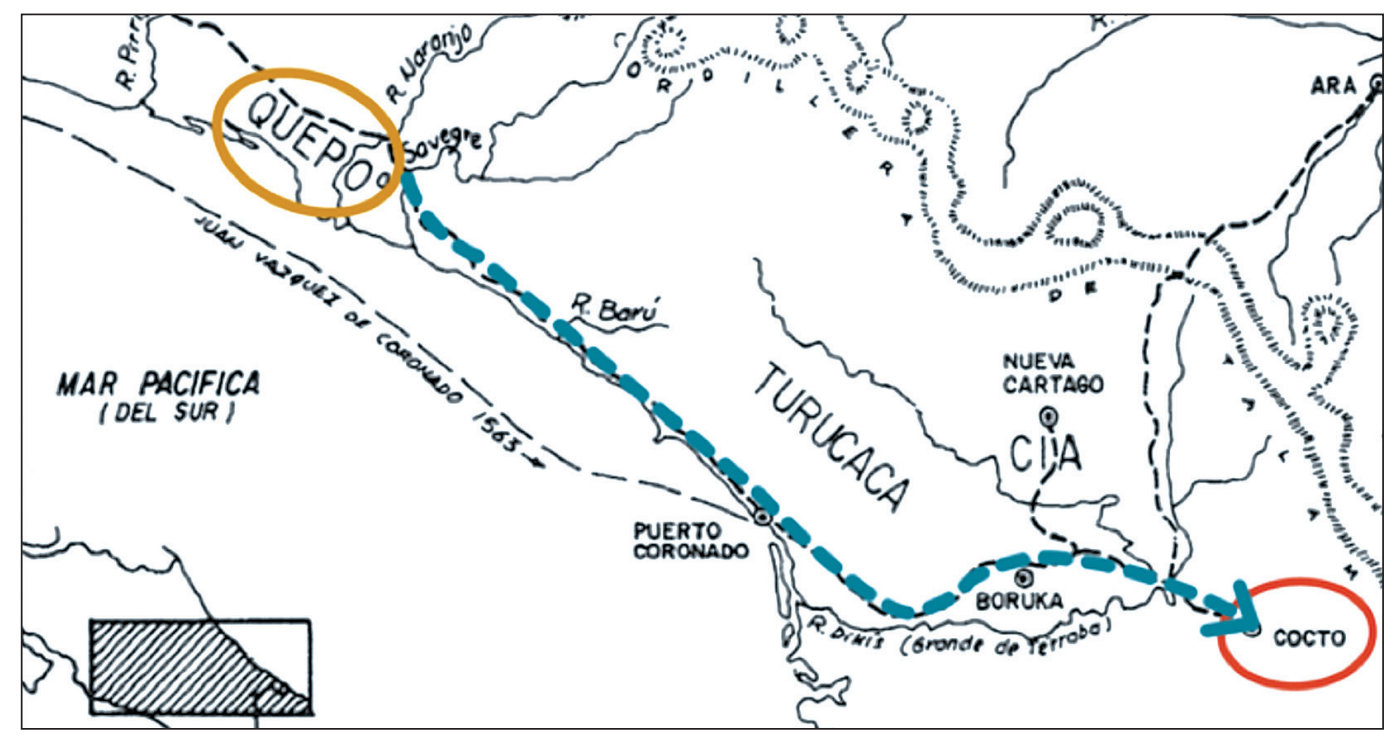

Figura 5. Detalle del mapa ilustrativo en donde se sitúan los poblados de Quepo y Cocto, correspondiente al siglo XVI (Molina 1993: 203) (Intervención propia)

Al visualizar en el mapa y compararlo con la plataforma Google Maps, Coronado pasó por lo que hoy se conoce como Bahía Ballena, se adentró por el territorio Boruca y atravesó el río Grande de Térraba, hasta poder cruzarlo después del territorio de Boruca y continuar hasta llegar a lo que se conoce actualmente como el cantón de Coto Brus, territorio fronterizo con Panamá.

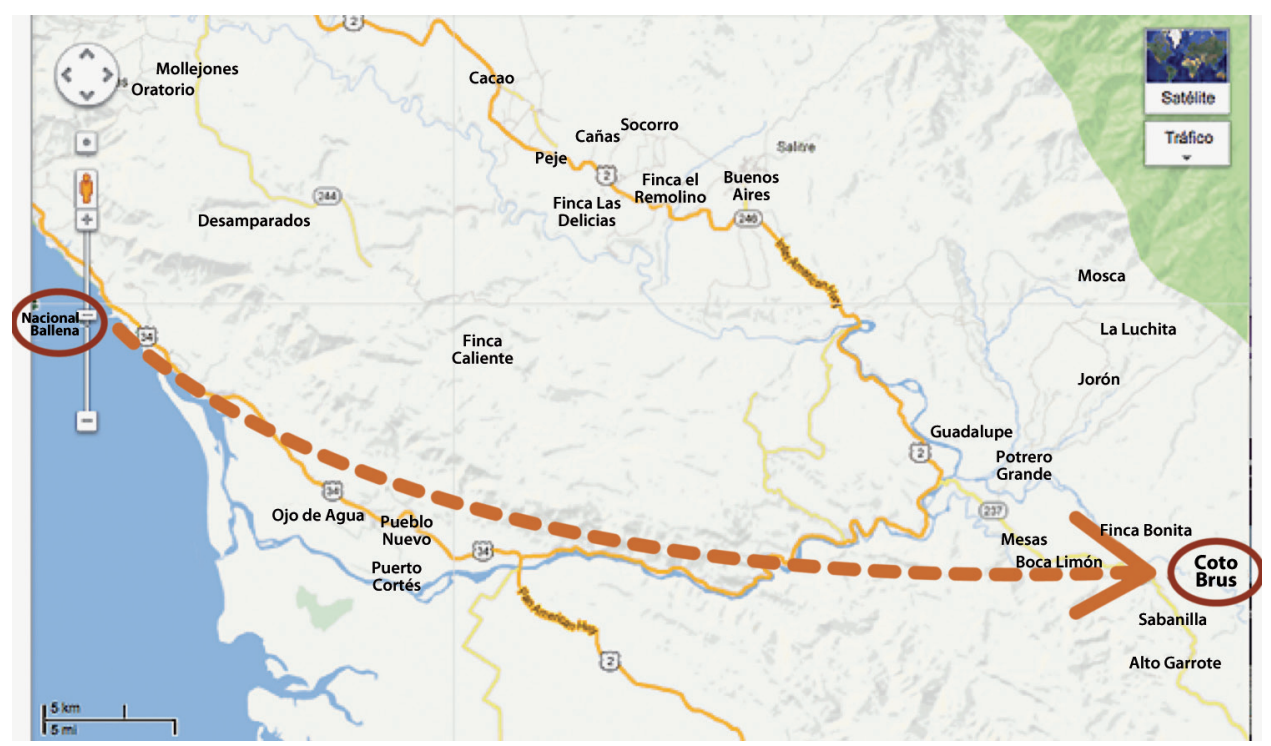

Figura 6. Detalle del Parque Marino Bahía Ballena a la izquierda y el territorio del cantón de Coto Brus a la derecha vistas por Google Maps (Intervención propia) 
Los Coctu contaban con más de mil seiscientos hombres de pelea, con variedad de armas y de gran fuerza; además tenían mujeres que les ayudaban en las guerras y que los españoles les dieron por sobrenombre como amazonas. Al respecto anota:

\begin{abstract}
Usan estos yndios por armas lanças de veynte palmos y mas, estolicas y rodelas de cuero crudio de anta, que son mas rezias que las nuestras...es gente lucida, labranse los braços y cuerpos, son yndios de buen juicio, tratan verdad, an despoblado con guerra mas de quarenta pueblos de su comarca; son riquísimos de oro, tienen mucho algodón, mays, frisoles, fruta, puercos de monte en gran cantidad, muchos venados. Ay en dos rios muy caudales que pasan cerca del pueblo mucho pescado, y en uno de que beben gran cantidad de truchas de nuestra España. (Fernández 1976: 97)
\end{abstract}

En la cita anterior Coronado describe datos similares en cuanto a la abundancia de alimentos que tenía este poblado, similar al que describió de Quepo. El atributo distintivo está en los cuerpos de estos indígenas al decir "labranse los braços y cuerpos", al mismo tiempo de resaltar la belicosidad y carácter guerrero de este territorio, al igual que el poderío de sus armas.

La figura $\mathrm{MNCR}^{1} 122$ muestra una serie de líneas curvas en el rostro y cuerpo de la talla en piedra. Las orejas poseen forma de espiral y las líneas curvas se prolongan en las mejillas. De igual forma otras líneas curvas se crearon alrededor del hombro y antebrazo y sobre sus genitales. Dichos trazos dan la idea de marcas en el cuerpo, sea por pigmento, tatuaje o cierta incisión.

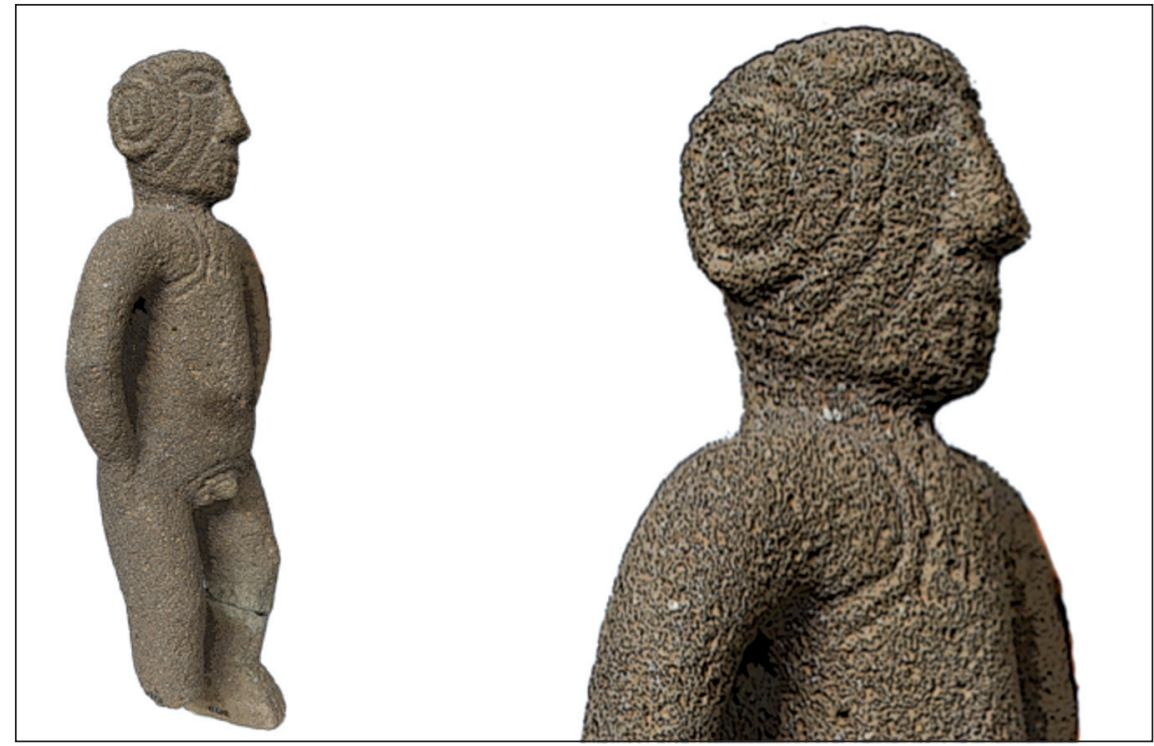

Figuras 7 y 8. Figura antropomorfa masculina con marcas en cara y cuerpo, MNCR 122. Valle Central, Aguacalientes, 1000-1550 d.C. Ígnea, andesita vesicular. Izq. Vista de tres cuartos. Der. Detalle (Vargas)

Los coctu capturan a sus enemigos y les cortan sus cabezas como trofeos: "Tienen junto al fuerte un cerrezuelo en que ay mucha cantidad de cabeças y cuerpos muertos de los que en la guerra cautivan, que los sacrifican, sino son mugeres y niños, que los tienen por esclavos hasta que mueren que mandan enterrallos consigo" (1976: 97). Esta cita testimonia que la muerte del enemigo se la da principalmente al hombre adulto y enemigo en las guerras, mientras que las mujeres y niños las capturaban y mantenían como esclavos. Esa certeza la tenía Corrohore para pedir el auxilio y rescate de su hermana y demás cautivos a Vázquez de Coronado. En ese pueblo belicoso trabajaban las mujeres, a la vez que sembraban e hilaban dos tipos de algodón. Eran muy ricos, pues se robaban el oro que extraían otros poblados de las minas y ríos. 
En la figura MNCR 11688, se observa un guerrero que porta una cabeza trofeo en su espalda. Dicho personaje posee una simplificación geométrica en su fisonomía. Su cabellera es larga y cae por su espalda en trenzas paralelas, al final se aprecia una cabeza trofeo. Al frente, el guerrero posa sus manos sobre el pecho, sus dedos se encuentran muy estilizados, ojos cuales semillas de café; rasgos similares posee la cabeza trofeo, la mandíbula saliente, la nariz arqueada y sus orejas simplificadas a medio círculo. Sus piernas se encuentran levemente flexionadas. Dicha estilización unifica en todo el conjunto escultórico que la armoniza. En la tesis de Carlos Aguilar (1952), se encuentra una ilustración similar a la fotografía tomada de la parte posterior de la pieza. La ilustración se hizo con la técnica del puntillismo para dar una sensación de textura de la roca.

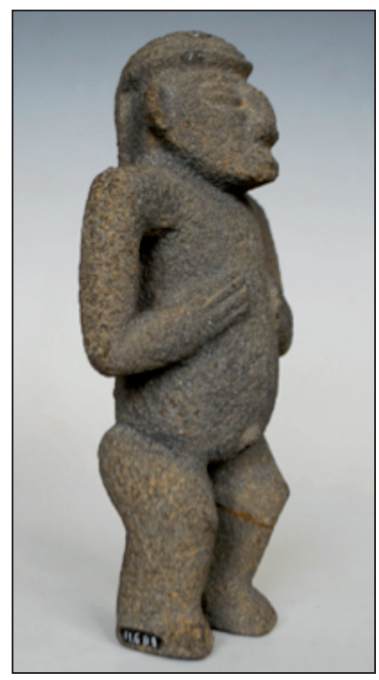

Figura 9. Figura antropomorfa masculina con una cabeza trofeo que cuelga en la espalda MNCR 11688. Vista de tres cuartos (Aguilar 1952)

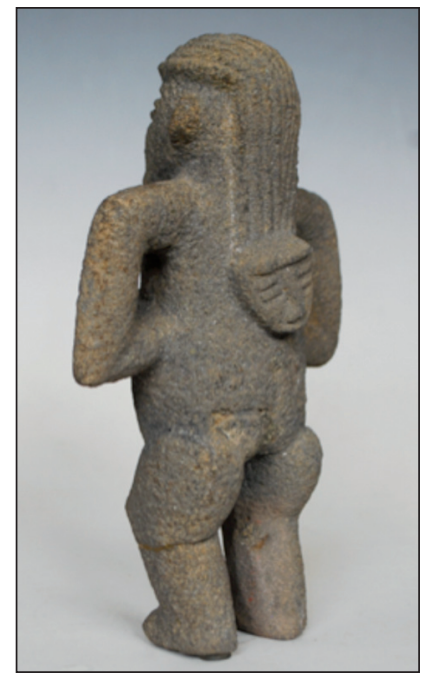

Figura 10. Figura antropomorfa masculina MNCR 11688 con una cabeza trofeo que cuelga en la espalda (Aguilar 1952)

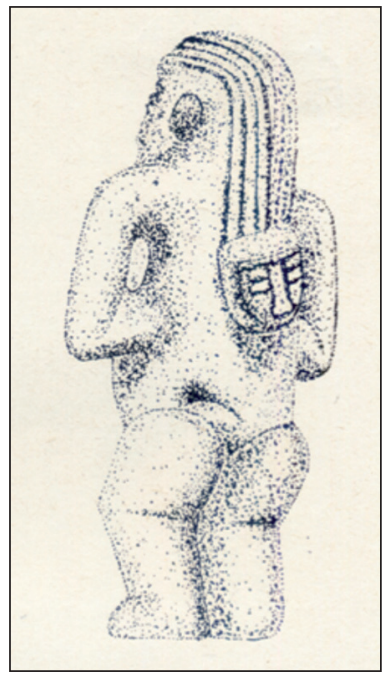

Figura 11. Ilustración de figura antropomorfa masculina con una cabeza trofeo que cuelga en la espalda (Aguilar 1952) 


\begin{abstract}
Las mugeres van a la guerra con sus maridos y ayudanles dandoles varas y lanças y tiran piedras, por cuyo respeto las llaman los Guetares y otras naciones biritecas, que es lo propio de las amazonas. Andan estos naturales con grandes señales de heridas por las continuas guerras. (Fernández 1976: 108)
\end{abstract}

Tienen campanales en que se sientan; son enemigos de sentarse en el suelo; tienen muy buena loça, ropa muy delgada de algodón; usan en ella labores de deshilado. (Fernández 1976: 108)

La pieza MNCR 12697 es una figura femenina de una guerrera que porta una cabeza trofeo en su espalda, similar a la pieza anteriormente analizada. Posee rasgos en el rostro similares a dicha figura. Sus bustos son escasos, la cadera más prominente, así como sus glúteos. Las manos sujetan una cuerda o cordón grueso que sostiene la cabeza trofeo a sus espaldas, la mano derecha, levemente más arriba que la otra y proporcionalmente más corta. El cabello es trenzado y cae hacia atrás y concluye donde inicia la cabeza colgante en la espalda. Es de destacar su ancha nariz terminada en forma triangular y labios prominentes, así como lo alargado de su cuello.

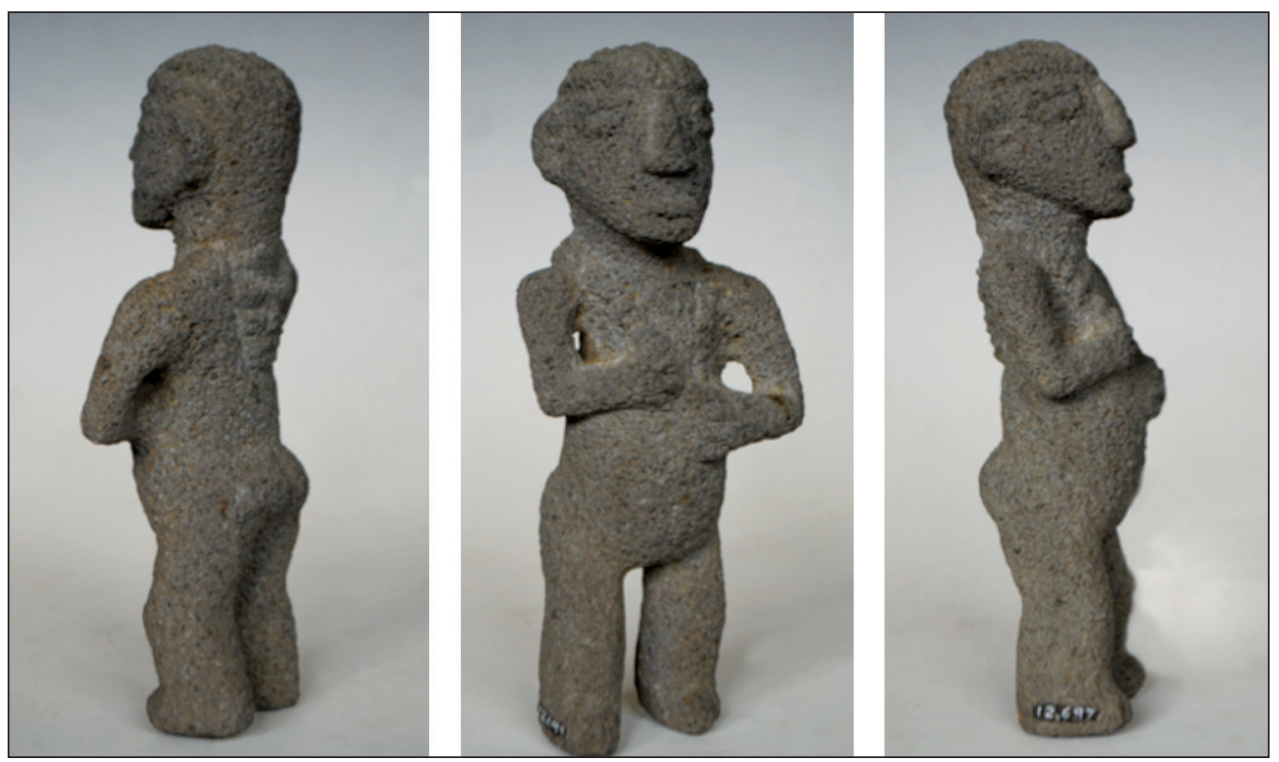

Figuras 12,13 y 14. Diferentes vistas de la figura antropomorfa femenina con cabeza trofeo colgada a su espalda y sujeta con una cuerda MNCR 12697, vistas posterior (tres cuartos), frente y lateral derecho (Vargas)

Carlos Aguilar agrupa en su tesis El complejo de las cabezas trofeo en la etnología costarricense (1952), muestra ocho categorías de representación entre guerreros de cabezas trofeo y prisioneros representados en diversos objetos de piedra, principalmente hallados en la Región Central del país y hacia la subregión del Caribe. En consecuencia detalla:

Podemos agrupar, para mayor facilidad de estudio, las manifestaciones de este complejo en la forma siguiente:
a) Guerreros (presencia de hacha),
b) Guerreros mostrando cabezas trofeo (presencia de hacha y cabeza trofeo),
c) Ostentadores de trofeo,
d) Cabezas trofeo,
e) Cuerpos trofeo,
f) Cabezas trofeo en objetos varios,
g) Prisioneros,
h) Cabezas trofeo y jaguares. 
Los objetos que integran este notable complejo arqueológico, están tallados generalmente en material volcánico y proceden principalmente de las faldas del Macizo Irazú-Turrialba, la cuenca del Reventazón y de las llanuras de Santa Clara y Matina, territorio que se ha considerado ocupado antiguamente por tribus del grupo Güetar. (Aguilar 1952: 7-8)

A continuación, Carlos Aguilar concluye sobre el tema de las cabezas y cuerpos trofeo:

La pieza más preciada para el vencedor es el guerrero enemigo, a quien se le decapitaba para hacer gala de su cabeza a modo de trofeo de guerra. También deben considerarse como trofeos de guerra los cuerpos de los enemigos, que entre los Cotos estaban expuestos en un árbol en asocio a las cabezas trofeo. (Aguilar 1952: 7)

Otro dato importante es que estos pueblos exhibían las cabezas y los cuerpos como trofeos y no para ingerirlos, esto se comprueba es este extracto "Avia seys dias que avian sacrificado siete yndios de la provincia de Ara y estavan frescos los cuerpos; de razon no deben comer carne umana; yo lo inquiri y me lo negaron" (Aguilar 1952: 97).

Los Coctos contaban con unos mil seiscientos "hombres de pelea" y una gran empalizada como una fortaleza con puertas levadizas. Junto a su fuerte hay gran cantidad de cabezas y cuerpo muertos que cautivan en guerra y luego sacrifican.

De gran valor es la descripción que hace Juan Vázquez del fuerte que tenían estos indígenas Coctos:

Para dar á vuestra señoria noticia en todo deste pueblo y fuerte era menester mucho papel y espacio. Estava asentado en una cuchilla de sierra; era de hechura de un huevo; tenia solas dos puertas, una al este y otra al ueste; era cercado de dos palizadas a manera de albaradas; tenia mucha cantidad de hoyos a la redonda; en las dos puertas tenia tres palizadas y los hoyos en mas cantidad; avia en el fuerte ochenta y cinco casas redondas, de cucuruchos como bovedas; cabrian en cada una dellas cuatrocientos hombres. Estaban las casas puestas por orden no vista: junto a la puerta estava una casa, luego delante dos y luego tres, y de tres en tres yvan ciertas hileras, de quatro en quatro yvan otras y a la otra puerta tornavan a disminuyr por la misma orden hasta quedar en una, en la proporcion dicha. Hacia la parte del norte avia una quebrada grañidísima, a la parte del sur otra no menor, por manera que solo podia ser ganado el fuerte por las dos puertas, y es asi que ganada la primera casa se avia de ganar las dos segundas, y ganadas estas las terceras, y asi por sus hileras tenian hechos callejones entre las casas, por las quales se mandavan en tal manera que las casas estavan algo altas del suelo, tenian troneras y estavan apartes de yndustria por cercar, por tal modo que dende ellas, sin ser vistos, herian los que entravan en el fuerte; y pasada la primer casa eran heridos de tres casas y pasadas las tres eras heridos de quatro sin ver quien los heria. Estase pintado el fuerte; holgaria que se acabase para que lo llevasen a V.S. ${ }^{a}$ Se decir que antes que viesen gente los nuestros se vieron heridos. Tiene otro fuerte junto aquel, que tendra doze casas: esta al modo destotro; abra en ambos mas de mill y seyscientos hombres de pelea. (Aguilar 1952: 97)

La descripción anterior del fuerte crea un plano que visto desde arriba tendría la forma de un tipo de barca, en la cual las puntas se encuentran en su extremos y la parte ancha en su centro. Observemos en la siguiente figura cómo se componía esta estructura, en la que se ha simplificado a treinta círculos ocres que representan los ranchos que a la vez están inscritos en un óvalo con la apertura en cada uno de sus lados (el este y oeste del fuerte), además de una doble empalizada alrededor y triple en ambas entradas; arriba un gran río (sector norte) y abajo uno más angosto (sector sur). Arriba a la derecha una cabeza pequeña representa el cerro con cabezas trofeo cercano a la entra para causar temor. Abajo a la izquierda el segmento de otro fuerte que Vázquez describió con una docena de ranchos. Por último, un eje horizontal, en rojo, cruza el fuerte principal de extremo a extremo. 


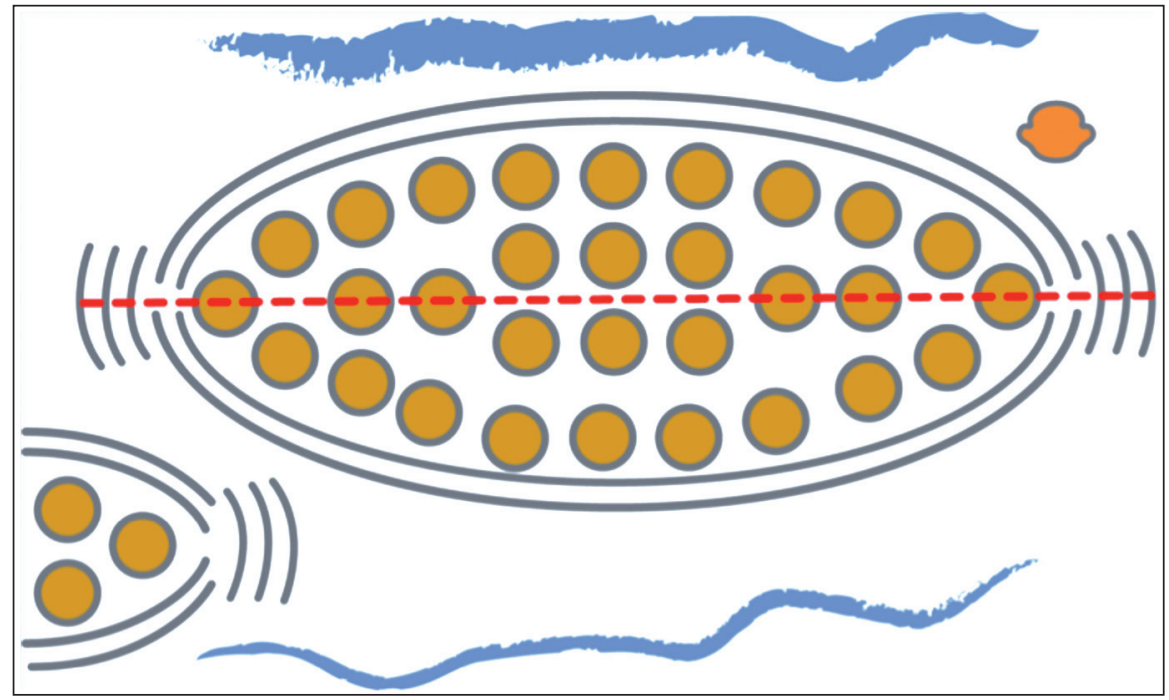

Figura 15. Imagen que representa la simplificación del fuerte de los Coctos descrito por Juan Vázquez de Coronado. Vista desde arriba (Vargas 2013)

El fuerte se convierte en un sistema de control en donde los Coctos vigilaban a sus enemigos desde la entrada o salida por medio de un mecanismo de ataque y de defensa sorpresivos "[...] y pasadas las tres eran heridos de quatro sin ver quien los heria" (Aguilar 1952: 97). Los medios naturales, como "la cuchilla de sierra" y los dos ríos sirvieron de estrategia de fuerte militar y de vivienda a la vez. La visión desde arriba, en este plano diseñado, permite identificar que entre más cercano esté un rancho a sus entradas hay más peligro y entre más cercano al centro hay más seguridad y protección para quienes lo habitan. La entrada del enemigo por las primeras casas, desde un rancho, luego dos, luego tres y después cuatro, causaba graves heridas a la víctima que entrase. Al respecto sobre el espacio obstruido apunta Michel Foucault:

\footnotetext{
El espacio cerrado, recortado, vigilado en todos sus puntos, en el que los individuos están insertos en un lugar fijo, en el que los menores movimientos se hallan controlados, en el que todos los acontecimientos están registrados, en el que un trabajo ininterrumpido de escritura une el centro y la periferia, en el que el poder se ejerce por entero [...] todo esto constituye un modelo compacto de dispositivo disciplinario. (Foucault 1993: 201)
}

En un primer momento, los Coctos tuvieron un enorme control ante sus enemigos. A Juan Vázquez y a sus hombres les costó tomar ese fuerte, pues al entrar por las empalizadas hirieron al capitán que envió y a unos veinte hombres y casi sin darse cuenta, debido a la estructura ya analizada, además de propiciarles fuertes quemaduras. A continuación, Vázquez regresa, les pide perdón y ordena rendir obediencia a su Majestad, los Coctos entran en plática con él hasta que al fin hacen las pases. El papel de Juan como mediador entre los indígenas y la voluntad del Rey se logra por medio de la palabra y no la fuerza, "sin que muriese a este tiempo yndo alguno" (Aguilar 1952: 106). El conquistador nombra en la segunda carta la existencia de más de treinta pueblos y siete palenques similares a los Coctos por esa zona.

Es con ayuda de unos cien indígenas de Corrohore que logran pacificar los Coctos. Además, rescataron a la hermana de Corrohore que se llamaba Dulcehe y al grupo de indígenas cautivos (mujeres e hijos). Para lograr el consenso, le entregaron a los soldados una docena de águilas y patenas de oro. Al final, Vázquez de Coronado consiguió hacer las pases 
entre Corrohore, el cacique de los Coctos, el de Turuca y el de Quepo. Parte del oro extraído por los Coctos lo sacaban de un río cerca del pueblo de Ucacara, un territorio que habían despoblado por la guerra.

\section{Sobre la cabeza y la decapitación}

Herbert Kühn en L’Ascension de l'Humanité (París 1958) señala que el decapitar cadáveres "marca el instante en que el hombre advierte la independencia del principio espiritual respecto a la totalidad vital representada por el cuerpo, y solo entierra la sede del espíritu" (Cirlot 2008).

Platón advierte que la cabeza humana "es la imagen del mundo" (Cirlot 2008). También se le considera el cielo o la cima del cuerpo. Para Cooper (2000) la cabeza se le considera la parte principal del cuerpo junto con el corazón, donde se encuentra la fuerza vital, el alma y la energía. Es donde reside la inteligencia y la locura. "Los cazadores de cabezas adquieren la fuerza vital y la fertilidad de la víctima".

Para Chevalier y Gheerbrant la cabeza simboliza el ardor del principio activo, la autoridad, el ordenar o esclarecer. Es el espíritu manifiesto con respecto al cuerpo, la manifestación de la materia. Se le compara con el universo por la forma esférica. "Es un microcosmos. Todos los sentidos convergen hacia el simbolismo del uno y de la perfección, del sol y de la divinidad" (Chevalier y Gheerbrant 1986: 81).

La talla en piedra de una figura antropomorfa de la subregión Valle Central, la MNCR 14926, pertenece a una mujer que sostiene con sus brazos extendidos un arco que gira sobre su cabeza y remata a los costados en dos cabezas más. Ambos elementos craneales son de un tamaño similar, la de la izquierda está dividida en tres partes, sin una forma específica, mientras que la derecha se define por su frente, ojos, nariz, mejillas, boca y barbilla.

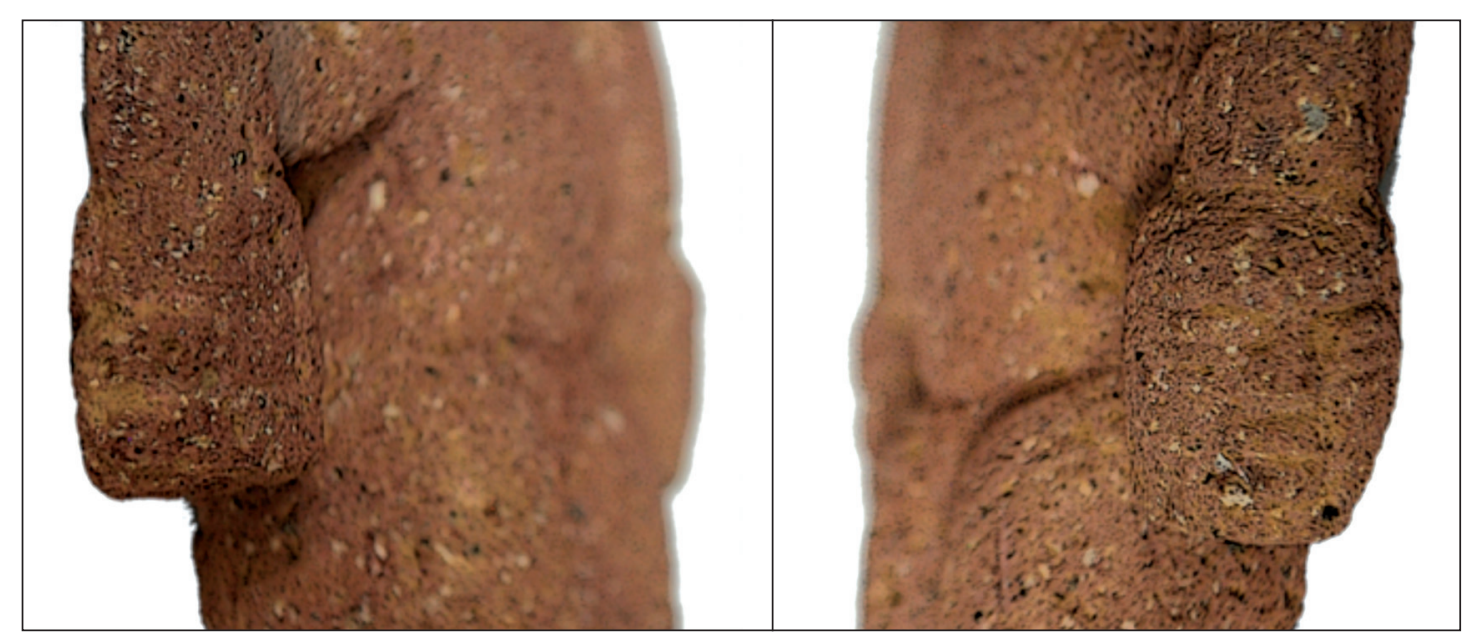

Figuras 16 y 17. Izq. Detalle de la cabeza izquierda de la figura antropomorfa femenina con tocado y una cabeza en cada extremo, MNCR 14926. Der. Detalle de la cabeza al costado derecho de la misma figura (Vargas)

En la figura completa de frente, se trazó en círculos las tres cabezas de la pieza, la de la mujer y las dos de sus costados a los extremos del arco. La curvatura comprende una 
circunferencia inconclusa, que si bien se dibuja completa se obtiene un centro que se ubica hacia la base del cuello y que continúa por las rodillas de la figura femenina, lo que crea un eje vertical de simetría; mientras que al proyectar un eje radial hacia cada cabeza de los extremos se logra una triangulación entre las tres cabezas. Dichas testas de los costados conforman el eje derecha e izquierda, la de la mujer el frente y atrás, mientras que la estructura de su cuerpo el eje central o el eje vertical del universo. Esto es similar al colocarse frente al sol -hacia el lugar donde nace este astro- en donde situamos el punto este al frente, el oeste atrás nuestro, el sur a la derecha y el norte a la izquierda. Por tanto, la figura resume los cinco puntos de cósmicos.

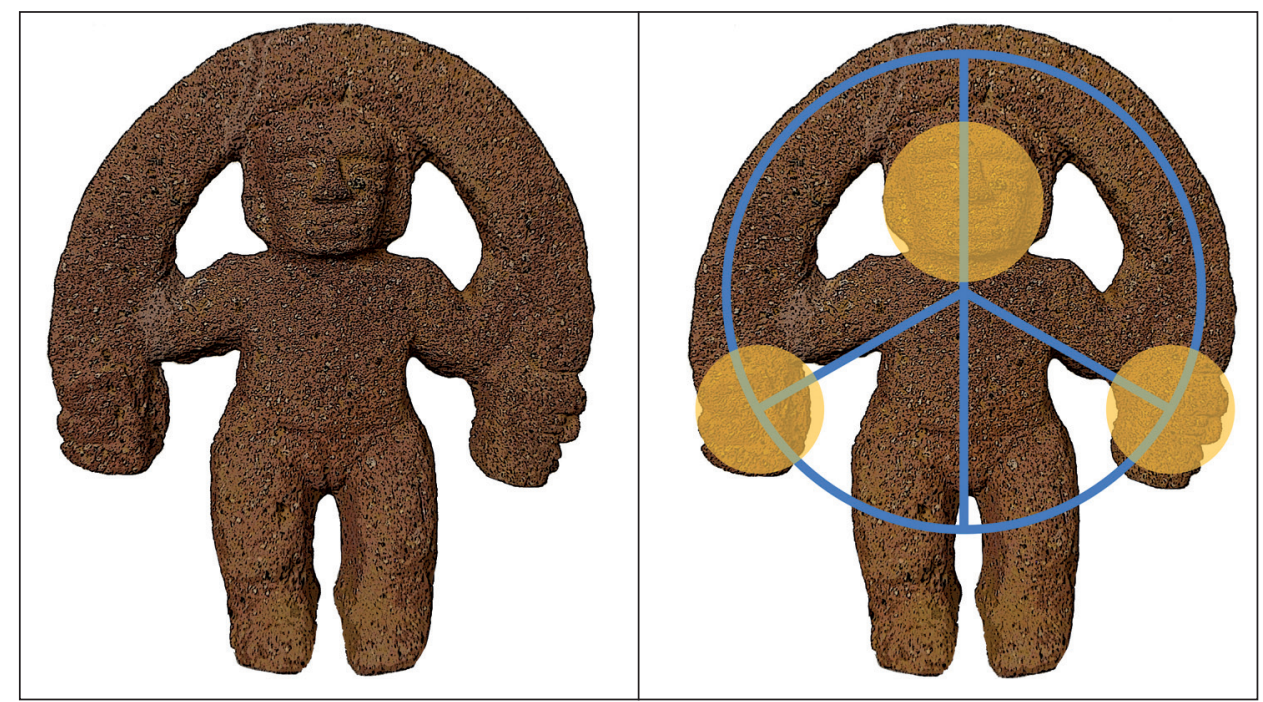

Figuras 18 y 19. Izq. Figura antropomorfa femenina con tocado y una cabeza en cada extremo, MNCR 14926. Valle Central, 1000-1550 d.C. Ígnea, andesita pumícea. Der. Estructura circular de la figura femenina con arco (Vargas)

Entre las piezas de oro que recibió Juan Vázquez por parte de Corrohore indica "diez pieças de oro de agulillas", a continuación sigue detallando "uvo entre ellas un grano de oro de rio que lo avian començado a labrar para patena y una agulilla nueva acabada de hazer" (Fernández 1976: 95). La referencia sobre el oro que detalla Juan Vázquez del poblado de Corrohore y posteriormente por parte de los Coctos y del cacique Turuca se debe a la riqueza aurífera del sur del país. Hay que hacer la distinción entre lo que son las piezas labradas (águilas y patenas) y una pieza en proceso o en grano que nombra.

En la colección de los museos de precolombinos de Costa Rica podemos admirar la variedad de obras de orfebrería que desarrollaron estos pueblos, en su mayoría los del sur del país. Entre las piezas de oro que describe Juan Vázquez de Coronado se encuentra la patena, lo que conocemos como disco de oro. En la colección de la torre del Museo Nacional de Costa Rica se exhibe la pieza número 20470, un disco conformado por un doble cordón de puntos y dos líneas dobles en sus extremos, cuatro cabezas hacia el centro y otro doble cordón lineal más cercano al centro. Si se trazan los ejes vertical y horizontal a la pieza podemos determinar que el círculo puede dividirse en cuatro sectores compuestos por esas cuatro cabezas. Los ejes distinguen cuatro puntos, comparables a los cuatro ejes del universo o el axis mundi que se detalla de seguido en las dos figuras siguientes. 

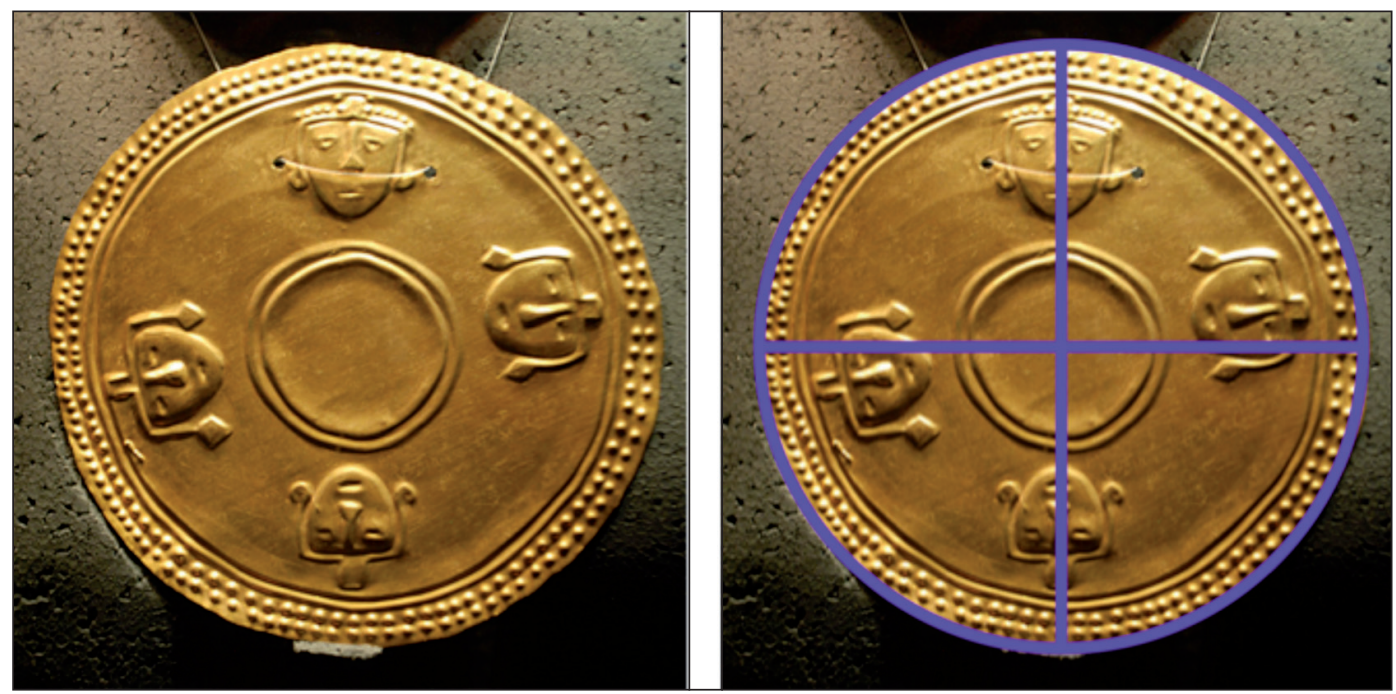

Figuras 20 y 21. Izq. Colgante circular. 16,5 cm de diámetro. Subregión Diquís. 700-1550 d.C. MNCR 20470. Der. Cuatro ejes trazados en el disco de oro que representa los ejes del universo (Vargas)

Sin duda la cabeza es un componente de enorme valor y cargado de poderes mágicos para la mitología costarricense. Se conoce también otras muchas piezas talladas en piedra; cabezas trofeo de guerreros que las colocan en la mano o sobre un costado del estómago, como señal de victoria sobre un enemigo. También, es sabido sobre la costumbre ritual utilizada en la reducción del tamaño de los cráneos, como lo representa el pintor español y fundador de la Escuela Nacional de Bellas Artes en Costa Rica, don Tomás Povedano en un óleo, en el que se representa las costumbres de los indígenas jíbaros del Ecuador. La obra pertenece a la colección del Banco Central de Costa Rica en San José y data de cerca de 1892 que pintó en Ecuador, antes de trasladarse a Costa Rica (Rojas 2003).

María Eugenia Bozzoli compiló un relato de los indígenas bribris en el que unos guerreros al matar a un poderoso sukia y cortarle su cabeza, esta se convierte en tigre y toma venganza. Primero mata a las aves de corral y animales domésticos y por último a la población indígena. La cabeza regresa a su pueblo y se lleva a su hija a una caverna. En la actualidad, es un sukia que cura a los que lo necesitan (1979: 81).

En una de las escenas del Popol Vuh, cuando cortan la cabeza de Hun-Hunahpú, la colocan en un árbol e inmediatamente empieza a dar frutos que son los jícaros. Posteriormente, aparece la doncella Ixquic que desea conocer los frutos del árbol. Aparece la cabeza de HunHunahpú, le arroja saliva en la mano y la deja embarazada de los gemelos Hunahpú e Ixbalanqué, héroes mayas que después se transformarán en el sol y la luna (Recinos 1947: 16-17).

\section{Conclusión}

La "visibilidad axial" que aprovechamos de Michel Foucault la hemos representado y aprovechado en dos grandes aspectos gráficos: en el primero por medio de un mapa que se comparó con la plataforma virtual Google Maps, en los cuales los puntos de referencia de lugares y espacios de la ilustración se cotejaron con las cartas de Juan Vázquez de Coronado del año 1563 y con la referencia satelital de este sistema de control planetario. 
En el segundo, por medio de las cartas de Juan Vázquez y el trazado en un programa de Adobe Ilustrador en donde se sintetiza desde la misma visión cartográfica y panóptica el fuerte militarizado de los indígenas coctos en el siglo XVI, al sur de nuestro país.

Algunas de las referencias en las cartas en cuanto a marcas en el cuerpo, cabezas trofeo, guerreros y guerreras lo pudimos comparar con piezas arqueológicas de piedra y de oro de la colección del Museo Nacional de Costa Rica. Las cartas de Juan Vázquez y las piezas arqueológicas forman parte de nuestro patrimonio cultural y el de los pueblos americanos que debemos evidenciar, valorar y acercar a nuestra sociedad.

Del mismo modo, la relación simbólica en conjunto con la representación visual ayuda a acercarnos más al simbolismo, a los significantes y significados que se encuentran detrás de las piezas arqueológicas que poseemos en las colecciones estatales.

\section{Notas}

1. Siglas empleadas para designar las piezas arqueológicas que pertenecen a la colección del Museo Nacional de Costa Rica (MNCR).

\section{Bibliografía}

Aguilar, Carlos H. 1952. El complejo de las cabezas trofeo en la etnología costarricense. San José: Trejos Hnos.

Bozzoli, María E. 1979. El nacimiento y la muerte entre los Bribris. San José: Editorial de la Universidad de Costa Rica.

Chevalier, J. y Gheerbrant. 1986. Diccionario de los símbolos. Barcelona: Herder.

Cirlot, Juan Eduardo. 2008. Diccionario de símbolos. Madrid: Ediciones Siruela.

Cooper, J. C. 2000. Diccionario de símbolos. Barcelona: Gustavo Gili.

Fernández, León. 1976. Conquista y poblamiento en el siglo XVI (relaciones histórico geográficas). San José: Editorial Costa Rica.

Foucault, Michel. 1993. Vigilar y castigar. Nacimiento de la prisión. Madrid: Siglo XXI Editores de C.V.

Kramer, Wendy, W. George Lovell y Christopher Lutz. 1993. "La conquista española de Centroamérica". En: Julio Cesar Pinto Soria. Historia General de Centroamérica, Tomo II. Madrid: Flacso.

Molina Montes de Oca, Carlos. 1993. Garcimuñoz. La ciudad que nunca murió. San José: EUNED.

Recinos, Adrián. 1947. Popol Vuh: Las antiguas historias del Quiché. México, D.F.: Fondo de Cultura Económica.

Rojas González, José Miguel. 2003. Arte Costarricense: un siglo. San José: Editorial Costa Rica.

\section{Medios electrónicos}

Google Maps (2013). Costa Rica [Mapa de calles]. Recuperado de: http://maps.google.co.cr/ 